\title{
Correction to: Identifying social media user demographics and topic diversity with computational social science: a case study of a major international policy forum
}

\author{
John Brandt ${ }^{1}$ (D) $\cdot$ Kathleen Buckingham ${ }^{1} \cdot$ Cody Buntain $^{2} \cdot$ Will Anderson $^{1}$. \\ Sabin Ray ${ }^{1} \cdot$ John-Rob Pool $^{1} \cdot$ Natasha Ferrari $^{1}$
}

Published online: 25 May 2020

(c) The Author(s) 2020

\section{Correction to: Journal of Computational Social Science (2020) 3:167-188 https://doi.org/10.1007/s42001-019-00061-9}

The article "Identifying social media user demographics and topic diversity with computational social science: a case study of a major international policy forum", written by John Brandt, Kathleen Buckingham, Cody Buntain, Will Anderson, Sabin Ray, John-Rob Pool, Natasha Ferrari was originally published electronically on the publisher's internet portal on 7th January 2020 without open access. With the author(s)' decision to opt for Open Choice the copyright of the article changed on 29th May 2020 to (C) The Author(s) 2020 and the article is forthwith distributed under a Creative Commons Attribution 4.0 International License (https://creativeco mmons.org/licenses/by/4.0/), which permits use, sharing, adaptation, distribution and reproduction in any medium or format, as long as you give appropriate credit to the original author(s) and the source, provide a link to the Creative Commons licence, and indicate if changes were made. The original article has been corrected.

Publisher's Note Springer Nature remains neutral with regard to jurisdictional claims in published maps and institutional affiliations.

\footnotetext{
The original article can be found online at https://doi.org/10.1007/s42001-019-00061-9.

John Brandt

john.brandt@wri.org

1 World Resources Institute, 10 G St NE \#800, Washington DC 20002, USA

2 University of Maryland, College Park, College Park, MD 20742, USA
} 